American J. of Engineering and Applied Sciences 5 (1): 78-83, 2012

ISSN 1941-7020

(C) 2014 N.W. Jusoh et al., This open access article is distributed under a Creative Commons Attribution

(CC-BY) 3.0 license

\title{
Purification of Natural Gas with Impurities using Membrane Processes: Parameter Estimation
}

\author{
Jusoh, N.W., K.K. Lau and A.M. Shariff \\ Department of Chemical Engineering, Research Centre for $\mathrm{CO}_{2}$ Capture, \\ Universiti Teknologi Petronas, Bandar Seri Iskandar, 31750, Tronoh, Perak, Malaysia
}

\begin{abstract}
Problem statement: Membrane processes have received a significantly high attention on natural gas separation processes since this technology provides higher operating and cost advantages as compared to other technologies. One of the major problems related to natural gas separation using membrane is the existence of feed impurities including $\mathrm{CO}_{2}$, heavy hydrocarbon and water. Approach: Hence, mathematical model that is able to study the effect of impurities towards the performance of the membrane is substantially crucial. In this study, a membrane transport model involves dual mode sorption and partial immobilization of the whole population was employed to predict the behavior of penetrant in the membrane. Results: Results related with sorption, diffusion, permeation and selectivity of Penetrants in the membrane were demonstrated in the present study. Conclusion/Recommendations: The sorbed concentration and permeability coefficient of a binary mixture were found to be lower as compared to pure gases, which represented the competition between Penetrants.
\end{abstract}

Key words: $\mathrm{CO}_{2} / \mathrm{CH}_{4}$ separation membrane process, dual mode model, parameter estimation

\section{INTRODUCTION}

Natural gas continues to be one of the world's important primary energy sources where the demand of the natural gas increases rapidly every year. Natural gas comes from the wells at different range of pressure and composition (Ahmadi et al., 2007). Low quality of natural gas that exceeds pipeline specification for carbon dioxide, water, nitrogen and hydrogen sulphide content faced with separation processes before it is delivered to the end-user's market. The presence of impurities might cause severe corrosion to the pipelines and equipments due to formation of acid when reacts with water, decrease the heating value of natural gas, dissipates the capacity of the pipeline and lead $\mathrm{SO}_{2}$ atmospheric pollution by combustion of natural gas contains $\mathrm{H}_{2} \mathrm{~S}$ (Bhide et al., 1998). The problems above can be overcome by applying several available processes and technologies including adsorption, absorption and cryogenic system. The foremost advantage of these separation processes is broadly commercialized in which the hydrocarbon loss is nearly insignificant. However, they are only applicable to separate $20 \%$ of carbon dioxide content. In addition, the absorption technology needs anti corrosion agent to be injected into the system continuously and adsorption process requires the regeneration stage to recover the adsorbent which involves larger space and increased weight. While, cryogenic system needs high energy consumption for the refrigerant compressor (Alias, 2004). One of the solutions is the application of membrane process to remove $\mathrm{CO}_{2}$ and impurities from natural gas. Different from other available technologies, membrane has the advantages of low weight and space necessity, low energy consumption, ease of operation and installation and high process flexibility.

Various studies have been conducted to investigate the membrane system processes. The research regarding the permeation rates of the different components has been reported by (Kohl and Nielson, 1997). A study conducted by Graham (1866) shown the separation of mechanism of a mixture of gases using rubber. Kohl and Nielson (1997) has performed the experiment on the low concentration of $\mathrm{CO}_{2}$ in separating natural gas. They have studied the effects of pressure, feed gas flow rate, temperature of a single stage membrane system. Lee et al. (1995) performed the field tests of membrane modules for the separation of carbon dioxide from low quality natural gas. In their study, they investigated the effects of pressure, feed flow rate and feed concentration (3-25 mole\% of $\mathrm{CO}_{2}$ ) in the feed. Amerongen (1950) and Barrer (1951) gave

Corresponding Author: Jusoh, N.W. Department of Chemical Engineering, Research Centre for $\mathrm{CO}_{2}$ Capture,

Universiti Technology Petronas, Bandar Seri Iskandar, 31750, Tronoh, Perak, Malaysia 
high contribution in the solution diffusion model development in presenting the membrane performance. Mathematical models for various flow patterns; cocurrent, counter current and cross flow have been developed and studied by Shindo et al. (1985) and Chen et al. (1994). In this study, membrane processes for gas separation involved with carbon dioxide is studied for gas sorption, permeability and selectivity variations which include the effects of operating condition; pressure by utilizing dual mode model. The model parameters are determined by fitting the model equation with the experimental data. The computed results are compared between pure and mixed gas experiment.

\section{MATERIALS AND METHODS}

Dual mode model: Dual mode model is applied to predict the effect of impurities on the performance of the membrane. This model is a phenomenological theory which gives greater representation of sorption, diffusion, permeation and selectivity of Penetrants in the membrane. Barrer et al. (1958) explained this model by indicating the concavity of sorption isotherm to the pressure axis. This model was extended to diffusion and permeation coefficient. This model combines Henry's law process, dissolved mode with the Langmuir sorption, where the penitent is believed to be adsorbed on the surfaces of micropores of polymer (Chandra, 2006).

The dual mode model is broadly applied in predicting membrane behavior due to its proven performance in a penetrant and polymer system, simplicity of mathematical equation, well founded fundamental basis and excellent agreement between experimental outcome and theoretical hypotheses (Ismail and Lorna, 2002). Furthermore, this model can be extended and described for binary and tertiary mixtures in analyzing the effect of penetrant in those mixtures where comparisons can be made with pure gas measurement.

Sorption mechanism is important to determine the solubility of penetrant in the membrane. This mechanism of the dual mode model is represented by Henry's law and Langmuir sorption which is given by Eq. 1:

$$
\mathrm{C}=\mathrm{C}_{\mathrm{D}}+\mathrm{C}_{\mathrm{H}}=\mathrm{K}_{\mathrm{D}} \mathrm{p}+\frac{\mathrm{C}_{\mathrm{H}}^{\prime} \mathrm{bp}}{1+\mathrm{bp}}
$$

Where:

$\mathrm{C}_{\mathrm{D}}=$ Concentration of penetrant in dissolved region

$\mathrm{C}_{\mathrm{H}}=$ Concentration of penetrant in the holes

$\mathrm{K}_{\mathrm{D}}=$ Henry's law/Dissolved mode sorption
$\mathrm{C}_{\mathrm{H}}{ }_{\mathrm{H}}=$ Langmuir/hole filling capacity of the polymer for a particular penitent

$\mathrm{b}=$ Langmuir affinity parameter

$\mathrm{p} \quad=$ Partial pressure of gas penetrant

Effective local diffusion is used to determine the diffusivity of the penetrant in the polymer. Koros (1977) proposed a partial immobilization model in diffusion coefficient where two sorption sites were present as shown in Eq. 2:

$\mathrm{D}_{\text {eff }}=\mathrm{D}_{\mathrm{D}}\left(\frac{1+\left(\mathrm{FK} /\left(1+\alpha \mathrm{C}_{\mathrm{D}}\right)^{2}\right)}{1+\left(\mathrm{K} /\left(1+\alpha \mathrm{C}_{\mathrm{D}}\right)^{2}\right)}\right)$

Where:

$$
\alpha=\frac{\mathrm{b}}{\mathrm{k}_{\mathrm{D}}} \mathrm{K}=\frac{\mathrm{C}_{\mathrm{H}}^{\prime} \mathrm{b}}{\mathrm{K}_{\mathrm{D}}} \text { and } \mathrm{F}=\frac{\mathrm{D}_{\mathrm{D}}}{\mathrm{D}_{\mathrm{H}}}
$$

$D_{D}$ and $D_{H}$ are Henry's law and Langmuir diffusion coefficients respectively. $F$ represent the ratio of diffusivity, $\mathrm{K}$ is the equilibrium constant.

In designing gas separation membrane, it is necessary to have the permeability of at least one component and the selectivity of the other component with respect to the first one. The permeability coefficient in the partial immobilization model is related to dual mode parameters are represented by Eq. 3:

$\mathrm{P}=\mathrm{k}_{\mathrm{D}} \mathrm{D}_{\mathrm{D}}\left(1+\frac{\mathrm{FK}}{1+\mathrm{b}_{\mathrm{A}} \mathrm{p}_{\mathrm{A}}}\right)$

Binary/Tertiary mixtures: The dual mode model is successfully extended for mixtures (component $\mathrm{A}$ and B) Eq. 4 and 5:

$$
\begin{aligned}
& \mathrm{C}=\mathrm{k}_{\mathrm{DA}} \mathrm{p}_{\mathrm{A}}+\frac{\mathrm{C}_{\mathrm{H}}^{\prime} \mathrm{b}_{\mathrm{A}} \mathrm{p}_{\mathrm{A}}+\mathrm{C}_{\mathrm{H}}^{\prime} \mathrm{b}_{\mathrm{B}} \mathrm{p}_{\mathrm{B}}}{\left(1+\mathrm{b}_{\mathrm{A}} \mathrm{p}_{\mathrm{A}}+\mathrm{b}_{\mathrm{B}} \mathrm{p}_{\mathrm{B}}\right)} \\
& \mathrm{P}=\mathrm{k}_{\mathrm{D}} \mathrm{D}_{\mathrm{D}}\left(1+\frac{\mathrm{FK}}{1+\mathrm{b}_{\mathrm{A}} \mathrm{p}_{\mathrm{A}}+\mathrm{b}_{\mathrm{B}} \mathrm{p}_{\mathrm{B}}}\right)
\end{aligned}
$$

All the parameters in the dual mode model for mixtures are pure component parameters. On the basis of the dual mode model, Koros assumed the diffusivity of gas in the polymer is not giving too much effect since the main effect of a mixture is due to the competition by a variety of penetrant for the fixed unrelaxed volume in the polymer.

The selectivity is essential to predict the performance of the membrane. Permselectivity is given 
$\alpha_{\mathrm{AB}}=\frac{\mathrm{y}_{\mathrm{A}} / \mathrm{y}_{\mathrm{B}}}{\mathrm{xA} / \mathrm{xB}}=\frac{\mathrm{J}_{\mathrm{A}} / \mathrm{J}_{\mathrm{B}}}{\mathrm{x}_{\mathrm{A}} / \mathrm{x}_{\mathrm{B}}}=\left(\frac{\mathrm{P}_{\mathrm{A}}}{\mathrm{P}_{\mathrm{B}}}\right)\left(\frac{\Delta \mathrm{p}_{\mathrm{A}} / \mathrm{x}_{\mathrm{A}}}{\Delta \mathrm{p}_{\mathrm{B}} / \mathrm{x}_{\mathrm{B}}}\right)$

Where:

$\mathrm{y}_{\mathrm{A}}$ and $\mathrm{y}_{\mathrm{B}}=$ Permeate concentration of component $\mathrm{A}$ and $\mathrm{B}$ respectively

$\mathrm{x}_{\mathrm{A}}$ and $\mathrm{x}_{\mathrm{B}}=$ Feed concentration of component $\mathrm{A}$ and $\mathrm{B}$ respectively

\section{RESULTS AND DISCUSSION}

Sorption isotherm for $\mathrm{CO}_{2}$ and $\mathrm{CH}_{4}$ that developed from the dual mode model is shown in Fig. 1. The sorption isotherm for both pure and mixed gases is concave to the pressure axis. The concentration of penetrant in the polymer is described as a function of pressure. Data from (Kamaruddin and Koros, 1997) is used to predict dual mode behavior of $\mathrm{CO}_{2}-\mathrm{CH}_{4}$ gas in the 6FDA-TADPO membrane.

The sorption isotherm parameters; $\mathrm{C}_{\mathrm{H}}, \mathrm{b}, \mathrm{k}_{\mathrm{D}}$ can be determined by nonlinear least-square regression (Kim and Hong, 2000) by fitting the dual mode model equation to the above experimental data for gas- polymer interaction. The estimated parameters are summarized in Table 1.

Figure 2 demonstrated the computed permeability versus pressure. Based on the results, the permeability of pure gases is represented as a function of upstream pressure and this permeability is dependent on pressure which is described by dual model and partial immobilization model (Chandra, 2006). The values of $\mathrm{D}_{\mathrm{D}}$ and $\mathrm{D}_{\mathrm{H}}$ of this model are also listed in Table 1 .

Koros suggested that the penetrant molecules in the membrane have partial mobility that lead to the permeability, where penetrant molecules diffuse in and out of the holes (Safari et al., 2009). The diffusion coefficient, $\mathrm{D}_{\mathrm{H}}$ shows the phenomena where penetrant go to the dissolved region from the hole and a situation where the penitent jumps from a dissolved mode to another are represented by $D_{D}$. Figure 3 shows the effective local diffusion coefficient of the membrane.

The separation efficiency or selectivity of membrane is vital in gas separation processes. Figure 4 shows the experimental and predicted values of $\mathrm{CO}_{2} /$ $\mathrm{CH}_{4}$ mixed gas selectivity.

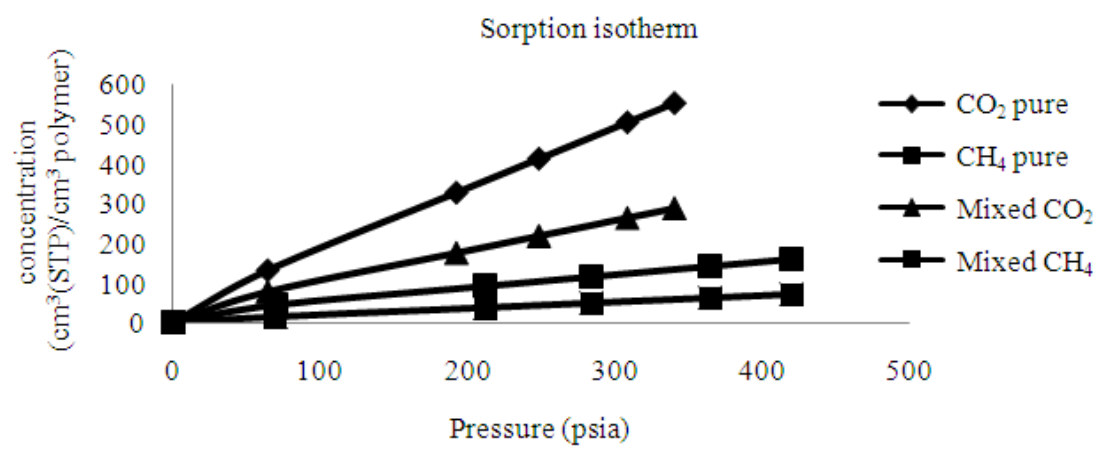

Fig. 1: Sorption isotherm for $\mathrm{CO}_{2}$ and $\mathrm{CH}_{4}$ (pure and mixed gas) in $6 \mathrm{FDA}-\mathrm{TADPO}$ at $35^{\circ} \mathrm{C}$

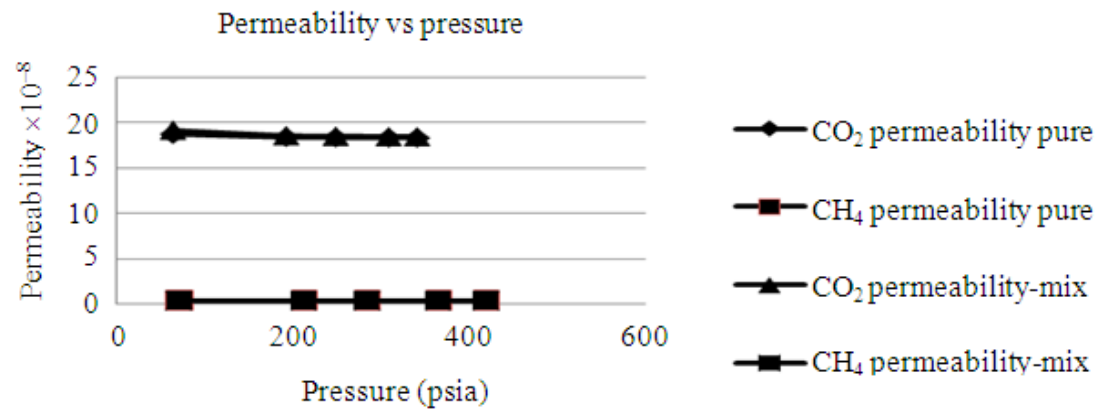

Fig. 2: Pressure dependency of permeability coefficients for $\mathrm{CO}_{2}$ and $\mathrm{CH}_{4}$ (pure and mixed gas) in 6FDA-TADPO at $35^{\circ} \mathrm{C}$ 
Am. J. Engg. \& Applied Sci., 5 (1): 78-83, 2012

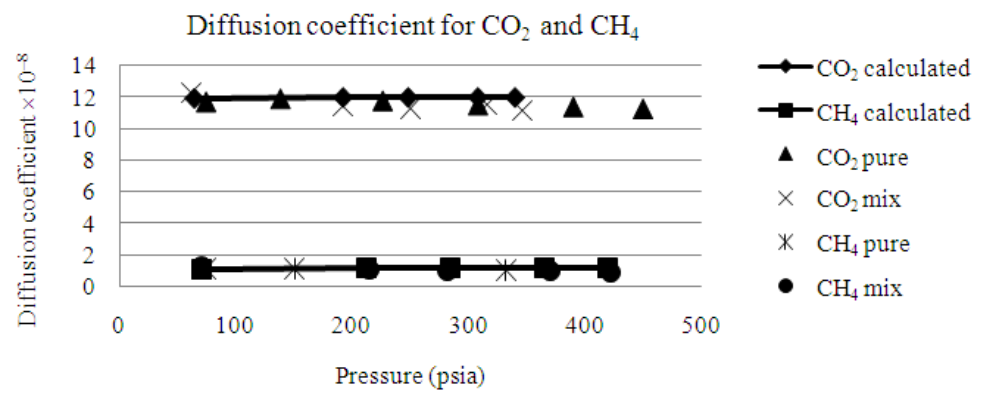

Fig. 3: Diffusion coefficient for $\mathrm{CO}_{2}$ and $\mathrm{CH}_{4}$ (pure and mixed gas) in $6 \mathrm{FDA}-\mathrm{TADPO}$ at $35^{\circ} \mathrm{C}$

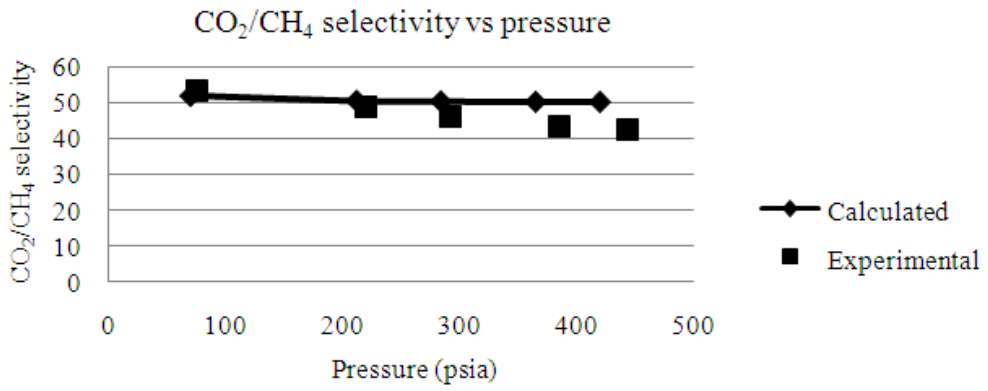

Fig. 4: Comparison of the experimental and calculated $\mathrm{CO}_{2} / \mathrm{CH}_{4}$ selectivity versus pressure

Table 1: Dual mode parameters

\begin{tabular}{lllllc}
\hline Gas & $\mathrm{K}_{\mathrm{D}}$ & $\mathrm{C}_{\mathrm{H}}^{\prime}$ & $\mathrm{b}$ & $\mathrm{D}_{\mathrm{D}}$ & $\mathrm{F}\left(\mathrm{D}_{\mathrm{D}} / \mathrm{D}_{\mathrm{H}}\right)$ \\
\hline $\mathrm{CO}_{2}$ & 1.526 & 34.084 & 1.023 & $1.196 \mathrm{E}-7$ & 0.084 \\
$\mathrm{CH} 4$ & 0.327 & 22.838 & 0.160 & $1.12 \mathrm{E}-8$ & 0.026
\end{tabular}

Units: $\mathrm{K}_{\mathrm{D}}\left(\mathrm{cm} 3(\mathrm{STP}) / \mathrm{cm}^{3} \cdot \mathrm{atm}\right), \mathrm{C}_{\mathrm{H}}{ }\left(\mathrm{cm}^{3}(\mathrm{STP}) / \mathrm{cm}^{3}\right), \mathrm{b}\left(\mathrm{atm}^{-1}\right), \mathrm{D}_{\mathrm{D}}$ $\left(\mathrm{cm}^{2} / \mathrm{s}\right)$

\section{DISCUSSION}

Based on the Fig. 1 and Table 1, the percentage decrease in sorption isotherm of mixed $\mathrm{CO}_{2}$ is much larger than $\mathrm{CH}_{4}$ compared to the pure component sorption isotherms This is due to the competitiveness effect between $\mathrm{CO}_{2}$ and $\mathrm{CH}_{4}$ for availability of a fixed number of Langmuir's sites in the case of mixed gas sorption (Kim and Hong, 2000). In addition, $\mathrm{CO}_{2}$ sorption in these microwaves is favorable and $\mathrm{CO}_{2}$ has higher affinity towards free volume defect sites than $\mathrm{CH}_{4}$ (Dhingra, 1997). Coupling effect is present in gas mixture where solubility coupling is considered by taking into account the thermodynamic and kinetic properties of gases in the polymer in describing the transport phenomena (Madden, 2005).

From Fig. 2 above, permeability depression in the mixed gas measurement is due to solubility effect and competition from Langmuir sites in the polymer between $\mathrm{CO}_{2}$ and $\mathrm{CH}_{4}$ (Dhingra, 1997). The data from Table 1 shows that the value of $\mathrm{CO}_{2}$ Langmuir affinity constant, $\mathrm{b}_{\mathrm{CO} 2}$ is higher than $\mathrm{CH}_{4}$. This phenomenon causes higher the depression of permeability coefficient for $\mathrm{CH}_{4}$ as compared to $\mathrm{CO}_{2}$ in a binary mixture. Furthermore, Langmuir hole filling capacity of $\mathrm{CO}_{2}$ is lesser than $\mathrm{CH}_{4}$ because the permeability of $\mathrm{CH}_{4}$ is lesser than $\mathrm{CO}_{2}$ since $\mathrm{CO}_{2}$ is closer to its critical point where the capability to fill up the holes is simple (Ismail and Lorna, 2002). Besides, permeability is decreased since mirovoids is saturated at a high level of penetrant and microwave situation appears at low concentration of penetrating that allow gas to pass through easily.

Based on Fig. 3, pressure increase leads to increase of diffusion coefficient (Chandra, 2006). A strong serving component of $\mathrm{CO}_{2}$ causes the diffusion increased due to swelling induced local facilitation of a local segmental motion when component present. On the other hand, larger molecule of $\mathrm{CH}_{4}$ may promote its diffusion by facilitation of local segmental motions.

From Fig. 4 above, the calculated selectivity is showing a good agreement with the experimental data at the lower range of pressure $<200$ psia. At higher pressure, the predicted value deviated from experimental data with maximum error of $18 \%$. The deviation may be contributed by the plasticization phenomena of $\mathrm{CO}_{2}$ in the membrane and bulk flux contribution in this process. 


\section{CONCLUSION}

The results for equilibrium sorption, permeability and diffusion coefficient graph of $\mathrm{CO}_{2}$ and $\mathrm{CH}_{4}$ in a 6FDA-TADPO membrane was shown to exhibit classical dual mode behavior. Sorption isotherm and permeability coefficient of pure gas are higher as compared to mixed gas due to the competition of binary components in mixed gas sorption. The decrease in solubility of $\mathrm{CO}_{2}$ sorption isotherm for mixed gas is higher than $\mathrm{CH}_{4}$ for mixed gas as compared to pure gas since the existence of $\mathrm{CO}_{2}$ tends to defect the free volume sites.

Depression of permeability coefficient of $\mathrm{CH}_{4}$ is higher than $\mathrm{CO}_{2}$ in a binary mixture because $\mathrm{CO}_{2}$ Langmuir affinity constant, b of $\mathrm{CO}_{2}$ is higher than $\mathrm{CH}_{4}$ which refers to intrinsic of penetrant, presenting the tendency of a penetrant to sorb into the unrelaxed voids in the glassy nonequilibrium polymer. The results of the diffusion coefficient showed that the increase in pressure will lead to the increase of diffusion coefficient. In addition, computed $\mathrm{CO}_{2} / \mathrm{CH}_{4}$ selectivity data was successfully validated by the experimental data.

\section{ACKNOWLEDGEMENT}

The researchers gratefully acknowledge to Carbon Dioxide- Mission Oriented Research $\left(\mathrm{CO}_{2}-\mathrm{MOR}\right)$ in providing financial support during this study.

\section{REFERENCES}

Ahmadi, G., C. Ji and D.H. Smith, 2007. Production of natural gas from methane hydrate by a constant downhole pressure well. Energy Convers. Manage., 48: 2053-2068. DOI: 10.1016/j.enconman.2007.01.015

Alias, A.N., 2004. Separation of moisture from natural gas using membrane separation, degree. Department of Chemical Engineering, Universiti Technology PETRONAS., Malaysia.

Amerongen, G.J.V., 1950. Influence of structure of elastomers on their permeability to gases. J. Polymer Sci., 5: 307-332. DOI: 10.1002/pol.1950.120050304

Barrer, R.M., 1951. Diffusion in and Through Solids. 1st Edn., Cambridge University Press, Cambridge, pp: 464.

Barrer, R.M., J.A. Barrie and J. Slater, 1958. Sorption and diffusion in ethyl cellulose. Part III. Comparison between ethyl cellulose and rubber. J. Polymer Sci., 27: 177-197. DOI: 10.1002/pol.1958.1202711515
Bhide, B.D., A. Voskericyan and S.A. Stern, 1998. Hybrid processes for the removal of acid gases from natural gas. J. Membrane Sci., 140: 27-49. DOI: $10.1016 / \mathrm{S} 0376-7388(97) 00257-3$

Chandra, P., 2006. Multi-component transport of gases and vapors in poly (ethylene terephthalate). Georgia Institute of Technology.

Chen, H., G. Jiang and R. Xu, 1994. An approximate solution for countercurrent gas permeation separating multicomponent mixtures. J. Membrane Sci., 95: 11-19. DOI: 10.1016/03767388(94)85024-0

Dhingra, S.S., 1997. Mixed gas transport study through polymeric membranes: A novel technique. State University, Blacksburg, Virginia.

Graham, T., 1866. On the absorption and dialytic separation of gases by Colloid Septa. Philosophical Trans. Royal Soc. London, 156: 399-439.

Ismail, A.F. and W. Lorna, 2002. Penetrant-induced plasticization phenomenon in glassy polymers for gas separation membrane. Separation Purification Technol., 27: 173-194. DOI: 10.1016/S13835866(01)00211-8

Kamaruddin, H.D. and W.J. Koros, 1997. Some observations about the application of Fick's first law for membrane separation of multicomponent mixtures. J. Membrane Sci., 135: 147-159. DOI: 10.1016/S0376-7388(97)00142-7

Kim, H.J. and S.I. Hong, 2000. The transport properties of $\mathrm{CO}_{2}$ and $\mathrm{CH}_{4}$ for chemically modified polysulfones. J. Applied Polymer Sci., 76: 391$400 . \quad$ DOI: $10.1002 /($ SICI)10974628(20000418)76:3<391::AID-APP14>3.0.CO;25

Kohl, A.L. and R.B. Nielson, 1997. Gas Purification. 5th Edn., Gulf Professional Publishing, Houston, Texas, ISBN-10: 0884152200, pp: 1395.

Koros, W.J., 1977. Sorption and Transport of Gases in Glassy Polymers. 1st Edn., University of Texas at Austin, USA., pp: 506.

Lee, A.L., H.L. Feldkirchner, S.A. Stern, A.Y. Houde and J.P. Gamezt et al., 1995. Field tests of membrane modules for the separation of carbon dioxide from low-quality natural gas. Gas Separation Purification, 9: 35-43. DOI: 10.1016/0950-4214(95)92175-C

Madden, W.C., 2005. The Performance of hollow fiber gas separation membranes in the presence of an aggressive feed stream. Georgia Institute of Technology. 
Am. J. Engg. \& Applied Sci., 5 (1): 78-83, 2012

Safari, M., A. Ghanizadeh and M.M. MontazerRahmati, 2009. Optimization of membrane-based $\mathrm{CO}_{2}$-removal from natural gas using simple models considering both pressure and temperature effects. Int. J. Greenhouse Gas Control, 3: 3-10. DOI: 10.1016/j.ijggc.2008.05.001
Shindo, Y., T. Hakuta, H. Yoshitome and H. Inoue, 1985. Calculation methods for multicomponent gas separation by permeation. Separation Sci. Technol., 20: 445-459. DOI: 10.1080/01496398508060692 